DOI: $10.19195 / 2084-5065.49 .8$

\title{
X-marks: Too simple to be useful?
}

\author{
RAYMOND MARQUIS
}

School of Criminal Justice, University of Lausanne, Switzerland

\section{TACHA HICKS}

School of Criminal Justice, University of Lausanne, Switzerland

\section{WILLIAMS MAZZELLA}

School of Criminal Justice, University of Lausanne, Switzerland

\section{Introduction}

Complexity of a handwritten entry is known to be a core element in reaching a conclusion by a valuable expert. To estimate the complexity of handwritten signatures, some quantitative models have been developed (Found et al., 1998). Whether we use such models or not, it is undeniable that a handwritten cross-mark is not complex: a cross-mark generally does not contain a lot of personal writing habits. We might therefore expect that cross-marks are too simple to enable handwriting examiners to discriminate a genuine from a simulated X-mark, and to discriminate between X-marks made by different people.

According to various authors (Hilton, 1982; Huber and Headrick, 1999; Foley, 1999; Welch, 1999), in spite of the apparent simplicity of $\mathrm{X}$-marks, several features can be considered to help determine the authorship of an X-mark, such as stroke length, direction, orientation, connection and sequence, as well as pen pressure, line quality and position of the crossing point. 
After a brief description of a case of ours that involved a questioned $\mathrm{X}$-mark, we will show how data collected for the case needs can help assess handedness of the writer of a questioned X-mark.

\section{The case}

As forensic document examiners, we recently faced a case involving an asset management agreement as a questioned document. On this document, which was made available to us in the original, an X-mark was handwritten in the box facing the line corresponding to the high-risk management type. After having lost his money, the client denied having written this $\mathrm{X}$-mark and declared that the X-mark was written by the bank employee.

We undertook the task of answering the following two questions: Is it possible to determine whether the client, or the bank employee, wrote the questioned $\mathrm{X}$-mark? Is the $\mathrm{X}$-mark compatible with a right-handed writer or a left-handed writer?

The questioned X-mark, which was observed under magnification (up to 30 times), appeared to be written with a blue ballpoint pen. The direction of the strokes of the questioned X-mark (see Fig. 1) could be determined without ambiguity, based on striae along the strokes, and ink deposits on the side of the cellulose fibers. It was unfortunately not possible to determine the sequence between the two strokes. On the basis of the direction of the strokes (see Fig. 2), we defined four categories for the construction of X-marks. According to this classification, the questioned $\mathrm{X}$-mark belonged to category $\mathrm{C}$.

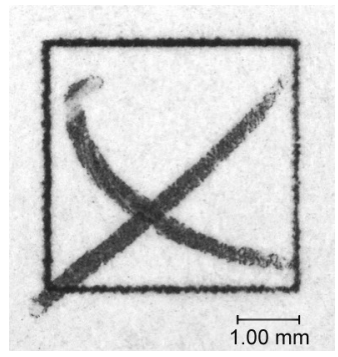

Figure 1. Illustration of the questioned X-mark

Source: own work.

Nowa Kodyfikacja Prawa Karnego 49, 2018

(C) for this edition by CNS 


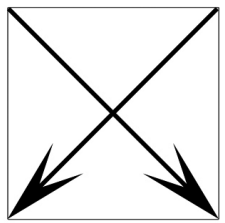

A

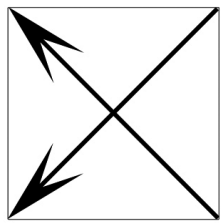

B

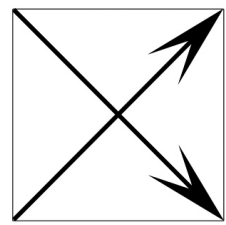

C

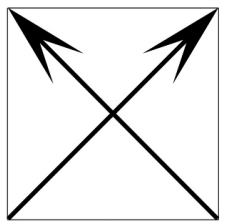

D

Figure 2. The four possible constructions of an X-mark based on the stroke direction that is shown by the arrows

Source: own work.

The client and the bank employee were called upon in turn and were requested to produce reference handwriting samples during a single session. The first task was to write, under dictation, a list of words and a text containing the letter $\mathrm{X}$. The second task was to solve mathematical operations and to write the answers in words, which included the letter $\mathrm{X}$ (during this task, we expected the writers would focus their attention on the mathematical operations instead of the writing process). The last task was to write X-marks in ballot boxes, on lottery tickets and, finally, in a multiple-choice questionnaire. A total of about $150 \mathrm{X}$ were written by each writer.

The session was video recorded, so we could later on determine the construction class of X-marks. It appeared that both the client and the bank employee were left-handed writers and used the same construction class A (which was consistent throughout the different tasks). This did not match the construction class of the questioned X-mark. We therefore concluded that neither the client nor the bank employee could be associated with the questioned X-mark.

\section{Experimental study}

To determine whether the questioned X-mark was compatible with a left-handed or a right-handed writer, an empirical study was carried out on a population of 52 writers, all members of the School of Criminal Justice of the University of Lausanne. Each person received a sheet of paper with 20 printed boxes, to be filled out with a ballpoint pen, while 
sitting at a table. We were present at the time of the sampling, so we could observe the direction of the strokes, and identify the construction (A, B, $\mathrm{C}$ or $\mathrm{D}$ ) of each writer. We noted that each person only used one X-mark construction class.

The results of this empirical study are reported in Table 1. Construction D was not represented in our sample. Construction B was only made by left-handed writers, while construction $\mathrm{C}$ was only made by right-handed writers. Based on these findings, the questioned X-mark, of construction $\mathrm{C}$, was not compatible with left-handed writers, but was compatible with right-handed writers.

Table 1. Results of the empirical study carried out within a population of 52 writers. A to D represent the four possible X-mark constructions (see Fig. 1)

\begin{tabular}{|c|c|c|c|}
\hline & $\begin{array}{c}\text { \# Observations in } \\
\text { left-handed writers }\end{array}$ & $\begin{array}{c}\text { \# Observations in } \\
\text { right-handed writers }\end{array}$ & Total \\
\hline A & 11 & 32 & 43 \\
\hline B & 2 & - & 2 \\
\hline C & - & 7 & 7 \\
\hline D & - & - & - \\
\hline Total & 13 & 39 & 52 \\
\hline
\end{tabular}

Source: own work.

To provide an answer in agreement with the ENFSI guidelines on evaluative reporting in forensic science (Willis et al., 2015), we must assign a value to a likelihood ratio (LR). In this case, the evidence $E$ is the fact that the questioned X-mark belongs to class $\mathrm{C}$. Based on this result, we aim to help discriminate the following two propositions: (1) the questioned X-mark was affixed by a right-handed writer, and (2) the questioned X-mark was affixed by a left-handed writer.

In short, our LR is the probability of the result if the first proposition is true, divided by the probability of the result if the second proposition is true. 
Let us consider that before our experiment, every construction class is equiprobable (we assume a uniform prior distribution). So, the same prior count of 1 can be assigned to every construction class. Let us further consider that the results of our experimental study modify this prior knowledge about distribution of X-mark construction classes in right and left-handed writers.

For both the left and the right-handed writers, Table 2 contains the prior counts, the observations made during the experimental study and the posterior counts. The latter are obtained by summing the prior counts with the observations. There is a practical advantage to consider such posterior counts: it solves the problem of 0 data. This procedure of updating distributions data was already presented in Biedermann et al. (2009) and recently used in Samie et al. (2016).

Table 2. Prior counts, observed data and posterior counts of the X-mark construction classes in populations of right and left-handed writers. The observed counts are those resulting from the experimental study carried out for the needs of the case (see Table 1). Posterior counts represent the sum of the prior counts with the observations

\begin{tabular}{|c|c|c|c|c|c|}
\hline \multicolumn{2}{|c|}{} & \multicolumn{2}{c|}{ Right-handed writers } & \multicolumn{2}{c|}{ Left-handed writers } \\
\hline Outcome & $\begin{array}{c}\text { Prior } \\
\text { counts }\end{array}$ & $\begin{array}{c}\text { Observa- } \\
\text { tions }\end{array}$ & $\begin{array}{c}\text { Posterior } \\
\text { counts }\end{array}$ & $\begin{array}{c}\text { Observa- } \\
\text { tions }\end{array}$ & $\begin{array}{c}\text { Posterior } \\
\text { counts }\end{array}$ \\
\hline A & 1 & 32 & 33 & 11 & 12 \\
\hline B & 1 & 0 & 1 & 2 & 3 \\
\hline C & 1 & 7 & 8 & 0 & 1 \\
\hline D & 1 & 0 & 1 & 0 & 17 \\
\hline Total & 4 & 39 & 43 & 13 & 1 \\
\hline
\end{tabular}

Source: own work.

Table 2 informs us that among 43 posterior counts for right-handed writers, 8 counts belong to class C. So, our probability of observing an $\mathrm{X}$-mark of class $\mathrm{C}$ if the writer is a right-handed writer is 8 out of 43 . 
On the other hand, among 17 posterior counts for left-handed writers, 1 count belongs to class $\mathrm{C}$. So, the probability of observing an X-mark of class $\mathrm{C}$ if the writer is a left-handed writer is 1 out of 17 . The LR becomes $(8 / 43) /(1 / 17)$, which is about 3 .

Our evidence is about 3 times more probable if the writer of the questioned X-mark is a right-handed writer, rather than a left-handed writer. This is not equivalent to say that the proposition of a right-handed writer is about 3 times more probable than the proposition of a lefthanded writer. Going from the first to the second affirmation would be committing a prosecutor's fallacy.

According to Bayes' theorem, in order to obtain the probabilities of the propositions given the evidence, we must multiply our LR value with prior probabilities that the writer is a right or a left-handed writer. These prior probabilities represent the view of the trier of fact that the writer of the questioned X-mark is a right or left-handed writer, given all the elements of the case, before considering the forensic results. For details on the calculation of posterior probabilities, see for example Robertson et al. (2016) and Marquis et al. (2017).

Let us first consider the situation where the trier of fact does not favour any of the propositions. Given fifty-fifty prior probabilities, our LR of 3 moves the probability that the writer of the questioned X-mark is a right-handed writer from 0.5 to 0.75 , and a left-handed writer from 0.5 to 0.25 .

Let us then consider a more realistic situation where the trier of fact takes as prior probabilities the proportion of right and left-handed writers in the general population. These are respectively about 0.9 and 0.1 (Huber and Headrick, 1999). Given such prior probabilities, our LR of 3 moves the probability that the writer of the questioned X-mark is a right handed-writer from 0.9 to 0.96 , and a left-handed writer from 0.1 to 0.04 .

We agree that providing values of posterior probabilities may be seen as going beyond the role of the expert, however this is useful to show the impact of the evidence on the probability of the propositions. These examples of posterior probabilities were thus communicated in our expert report, together with our likelihood ratio value, to answer the second question of the court. 


\section{Conclusion}

The case presented in this article shows that useful results can be obtained even with simple writings. In this case the stroke direction could be determined without ambiguity. This is generally possible if the writing instrument used is a ballpoint pen, but it can be very difficult depending on the writing instrument.

The magnitude of the LR obtained in this case was low by using the direction of the strokes only. A better discrimination could be achieved if we were able to determine the sequence between the two strokes, which would lead to eight possible X-mark construction classes. A better discrimination could also be achieved, in other cases, by including other features (if any), for example the direction of horizontal strokes of characters $f, t$, and direction of the movement of the letter $o$ (Conrad, 2008).

Since a LR value was derived from the data collected for the case needs, the ENFSI guideline was satisfied without difficulty. In this respect, we hope that this paper will encourage handwriting examiners to collect data and to make efforts to follow the recommendations of the ENFSI guideline on evaluative reporting in forensic science.

\section{References}

Biedermann A., Taroni F., Bozza S. (2009), "Implementing statistical learning methods through Bayesian networks. Part 1: A guide to Bayesian parameter estimation using forensic science data", Forensic Science International 193, pp. 63-71.

Conrad M. (2008), "Left-hand writing vs. right-hand writing", Journal of the American Society of Questioned Document Examiners 11, pp. 19-27.

Foley D.N. (1999), “'X'/Cross marks - still used today”, SAFDE meeting, Conyers.

Found B., Rogers D., Rowe V., Dick D. (1998), "Statistical modeling of expert's perceptions of the ease of signature simulation", Journal of Forensic Document Examination 11, pp. 73-99.

Hilton O. (1982), Scientific Examination of Questioned Documents, rev. ed., Elsevier, Amsterdam.

Huber R.A., Headrick A.M. (1999), Handwriting Identification: Facts and Fundamentals, CRC Press, Boca Raton.

Marquis R., Cadola L., Mazzella W., Hicks T. (2017), "What is the error margin of your signature analysis?" Forensic Science International 281, e1-e8. 
Robertson B., Vignaux G.A., Berger C.E.H. (2016), Interpreting Evidence: Evaluating Forensic Science in the Courtroom, 2nd ed., John Wiley \& Sons, Chichester.

Samie L., Hicks T., Castella V., Taroni F. (2016), "Stabbing simulations and DNA transfer", Forensic Science International: Genetics 22, pp. 73-80.

Welch T. (1999), "The mark and obliteration of the 'X', International Journal of Forensic Document Examiners 5, pp. 245-248.

Willis S., McKenna L., McDermott S. et al. (2015), ENFSI Guideline for Evaluative Reporting in Forensic Science.

\section{Summary}

This paper presents a case illustrating the value that can be elicited from simple handwritten entries such as X-marks. An experimental study was carried out for the case needs, where X-marks were collected from a population of 52 writers and classified according to the stroke direction. To fulfil the recommendations of the ENFSI guideline on evaluative reporting in forensic science, the results of this study were used to quantitatively assess handedness of the writer of the questioned X-mark.

Keywords: X-marks, handedness, forensic interpretation, evidence assessment, likelihood ratio. 